\section{Orale Erdnuss-Immuntherapie funktioniert}

\author{
Patienten mit einer schweren Erdnussallergie leben in steter Angst \\ vor einer anaphylaktischen Reaktion. Notfallmedikamente sind \\ ein Sicherheitsanker, zusätzlichen Schutz könnte die orale Hypo- \\ sensibilisierung bieten.
}

Er rste Erfahrungen mit der oralen Immuntherapie (OIT) bei Erdnussallergie konnten Pädiater aus Berlin und New York, USA, jetzt in einer offenen Studie sammeln. Einbezogen waren 23 Kinder im Alter zwischen 3,2 und 14,3 Jahren mit einer IgE-vermittelten und im doppelblinden und plazebokontrollierten Provokationstest (DBPCFC) festgestellten Erdnussallergie. Die OIT mit gerösteten Erdnüssen wurde in einem siebentägigen Rush-Protokoll eingeleitet, bei Nichterreichen der protektiven Dosis von mindestens $0,5 \mathrm{~g}$ erhielten die Patienten eine Langzeitauftitration mit Dosissteigerungen alle zwei Wochen. Die Erhaltungsphase betrug acht Wochen. Nach zweiwöchiger Erdnusskarenz wur- de ein nochmaliger DBPCFC zur Erfolgskontrolle durchgeführt.

Nach der Rush-Aufdosierung über sieben Tage tolerierten die Patienten lediglich eine Dosis von median 0,15 g Erdnüssen. 22 der 23 Patienten unterzogen

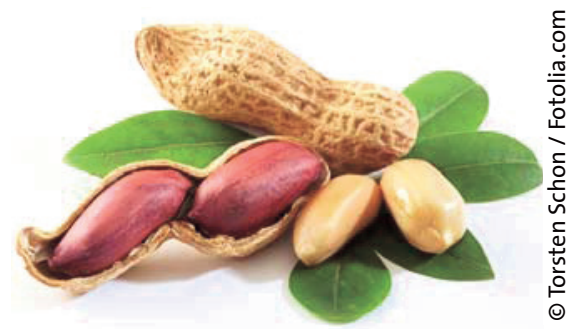

Immerhin $1 \mathrm{~g}$ der Hülsenfrucht vertragen Erdnussallergiker im Median nach sieben Monaten oraler Immuntherapie. sich daraufhin der Langzeitaufdosierung. Nach sieben Monaten erreichten $14 \mathrm{~Pa}-$ tienten die anvisierte Schutzdosis von $0,5 \mathrm{~g}$ Erdnüssen, im finalen DBPCFC wurde median $1 \mathrm{~g}(0,25-4 \mathrm{~g})$ vertragen im Vergleich zu median 0,19 g $(0,02-1 \mathrm{~g})$ im DBPCFC vor der Erdnuss-OIT. Bei 2,6\% von insgesamt 6.137 oral applizierten Einzeldosen traten leichte bis mäßige Nebenwirkungen auf, bei vier der 22 Patienten musste die Behandlung wegen schwerer Nebenwirkungen abgebrochen werden. Das erdnussspezifische $\mathrm{IgG}_{4}$ stieg an, die Konzentration von spezifischem IL-5, IL-4 und IL-2 war nach der OIT vermindert.

Fazit: Die orale Immuntherapie mit Erdnüssen bei allergischen Patienten ist machbar und bringt für über die Hälfte von ihnen eine deutlich gesteigerte Toleranz gegen das Allergen.

$b k$

Blümchen $\mathrm{K}$ et al. Oral peanut immunotherapy in children with peanut anaphylaxis. J Allergy Clin Immunol 2010; 126: 83-91

\title{
Modifizierte dendritische Zellen bewähren sich bei der Maus
}

Der weltweite Vormarsch von Allergien forciert das Interesse an neuen Therapiemethoden, die spezifisch an einem frühen Agens der allergischen Reaktionskaskade ansetzen. Im Mäuseversuch wurde jetzt die Wirksamkeit genetisch modifizierter dendritischer Zellen erprobt.

M it Hilfe der „small interfering RNA“ (siRNA) lässt sich selektiv die Expression bestimmter Gene hemmen. Diese Entdeckung von Andrew Fire und Craig Mello wurde 2006 mit dem Nobelpreis für Medizin ausgezeichnet. Auch die in der Allergiekaskade wichtigen antigenpräsentierenden Zellen, die dendritischen Zellen (DC), können durch siRNA modifiziert werden. Wird z.B. die Expression des CD40Gens von aus Knochenmark gewonnenen DC durch eine Transfektion mit CD40-siRNA gehemmt, erhält man CD40-freie DC.

Solche CD40-freie DC wurden jetzt in einer Experimentalstudie zunächst in vitro mit Ovalbumin gepulst und diese genetisch modifizierten und allergengepulsten Zellen dann Mäusen injiziert. In der anschließenden intranasalen Provokation mit Ovalbumin waren derart behandelte Mäuse im Vergleich zu Kontrollmäusen besser vor allergischen Reaktionen geschützt. Dabei spielte es keine Rolle, ob die Mäuse bei Applikation der CD40-freien DC schon gegen Ovalbumin sensibilisiert waren oder erst nach der DC-Behandlung sensibilisiert wurden. Auch die AntiOvalbumin-IgE-Spiegel im Serum sanken im Vergleich zu denen der Kontrollmäuse deutlich ab. Außerdem unterdrückten die CD40-freien OVA-DC die Infiltration von Eosinophilen in die Nasenschleimhaut und verminderten die Ovalbumin-spezifischen T-Zell-Antworten, die T-Zell-Produktion von IL-4 und IL-5 nach der Provokation sowie die CD4+CD25-T-Zell-Antworten. Die Wirkung der mit Ovalbumin gepulsten DC war spezifisch gegen die allergischen Reaktionen auf Ovalbumin gerichtet, allergische Reaktionen gegen andere Allergene, gegen welche die Mäuse sensibilisiert worden waren, wurden nicht unterdrückt.

Fazit: Genetisch modifizierte dendritische Zellen, bei denen gezielt die Expression des CD40-Gens gehemmt wurde und die in vitro mit einem Allergen gepulst wurden, reduzieren im Tierversuch die Symptome von IgE-vermittelten Allergien. Die induzierte Toleranz ist allergenspezifisch. Ob sich diese spezifische zelluläre Immuntherapie auch für den Einsatz beim Menschen eignet, kann noch nicht beurteilt werden. $b k$

Suzuki $M$ et al. A novel allergen-specific therapy for allergy using CD40-silenced dendritic cells. J Allergy Clin Immunol 2010; $125: 737-43$ 